УДК 903.01/.09

https://doi.org/10.24852/2587-6112.2020.5.55.61

ББК 63.4(2)

\title{
ЭВОЛЮЦИЯ СИСТЕМЫ ПИТАНИЯ НАСЕЛЕНИЯ ВЕРХНЕГО ПОВОЛЖЬЯ В ЭПОХУ ПЕРВОБЫТНОСТИ
}

\section{(C) 2020 г. В.С. Беляева}

В статье прослежена эволюция системы питания населения Верхнего Поволжья на основе анализа археологических данных наиболее изученных памятников мезолита, неолита, бронзового века и раннего железного века, расположенных в пределах современной Тверской области. Автором рассматривается краткая предыстория изучения систем жизнедеятельности. Система питания анализируется на протяжении двух связанных между собой, но отдельных этапов первый из которых - мезолит, неолит и второй - бронзовый, ранний железный век. Для изучения системы питания была использована ранее разработанная программа анализа систем жизнеобеспечения, которая включает 59 информативных блоков и 345 признаков. На основании полученных данных было выявлено, что система питания на протяжении тысячелетий первобытной истории была представлена всеми видами занятий, которые так или иначе связаны с добычей, приготовлением и сохранением пищи. Рыболовство и собирательство практиковались на протяжении обоих этапов как обязательные первичные производства, однако, охота получила большее развитие в бронзовом и раннем железном веках. Адаптируясь к условиям природной среды, население Верхнего Поволжья сумело создать успешную систему жизнеобеспечения для развития и роста населения.

Ключевые слова: археология, Верхнее Поволжье, эпоха первобытности, программа описания, база данных археологических памятников, эволюция систем жизнеобеспечения, система питания.

\section{EVOLUTION OF THE NUTRITION SYSTEM OF THE POPULATION OF THE UPPER VOLGA REGION IN THE PRIMEVAL PERIOD}

\section{V.S. Belyaeva}

The article traces the evolution of the nutrition system of the population of the Upper Volga region based on an analysis of archaeological data obtained at the most thoroughly studied monuments of the Mesolithic, Neolithic, Bronze Age and early Iron Age, located within the contemporary Tver region. The author considers a summary of the background information related to the study of the household systems. The nutrition system is analyzed for two related, but separate stages, the first of which was the Mesolithic, Neolithic and the second one was the Bronze and Early Iron Ages. A previously developed program for analyzing life support systems was used to study the nutrition system, which includes 59 informative blocks and 345 attributes. Based on the obtained data, it was revealed that for thousands of years of primitive history the nutrition system was represented by all types of activities generally associated with the extraction, preparation and preservation of foodstuffs. Fishing and gathering remained mandatory primary production for the two stages, but hunting was more developed in the Bronze and Early Iron Ages. In the course of adapting to the conditions of the natural environment, the population of the Upper Volga region managed to create a successful life support system for the development and growth of the population.

Keywords: archaeology, Upper Volga region, primeval period, description program, archaeological monument database, evolution of household systems, nutrition system.

На протяжении всей эпохи первобытности окружающая среда была главным фактором, который определял систему жизнеобеспечения населения. Поскольку именно на ранних стадиях развития человечества внешняя среда активно менялась, постоянно изменялась и сложившаяся до этого система жизнеобеспечения. Актуальной проблемой остается эволюция систем жизнеобеспечения, а также главной ее составляющей - системы питания населения, методы изучения данной пробле- мы и особенности формирования систем жизнеобеспечения в зависимости от условий и ресурсов региона, археологической культуры.

Теоретические основы изучения системы жизнеобеспечения древних обществ разрабатывали Э.С. Маркарян, С.А. Арутюнов, И.А. Барсегян (Культура ..., 1983). Этнографами в употребление было введено понятие «культура жизнеобеспечения», которая в свою очередь направлена на поддержание жизне- 
деятельности ее носителей. Главную роль отводили материальному компоненту потребительской сферы (жилье, одежда, пища). В статье «Проблемы исследования культуры жизнеобеспечения этноса» предлагается новый метод для исследования компонентов культуры жизнеобеспечения - на основе списка возможных объектов потребления и их использования/оформления (Арутюнов, Маркарян, Мкрутумян, 1983, с. 22-31).

И.И. Крупник характеризует системы жизнеобеспечения как «...экологически обусловленные формы социального поведения, которые обеспечивают человеческому коллективу существование за счет ресурсов конкретной среды обитания» (Крупник, 1989, c. 15).

Несколько иная позиция представлена В.И. Козловым: исследователь считает, что «жизнеобеспечение человека как социально-биологического существа означает удовлетворение его социальных и биологических потребностей» (Козлов, 1991, с. 16). В.И. Козлов одним из первых начинает учитывать одновременно две основные стороны жизнеобеспечения людей - физическую и психическую.

Б. Фаган и К. ДеКорс предлагают структуру комплексов источников по изучению системы жизнеобеспечения, в которую должны входить сведения, относящиеся к окружающей среде, кости животных (остатки фауны), остатки растений, кости людей, копролиты, артефакты (Фаган, ДеКорс, 2007, с. 316-432).

Критически относится к данной структуpe А.Н. Ямской, который утверждал, что все современные определения более похожи на «адаптацию» или «хозяйственно-культурный тип», скорее всего, это заимствование из англоязычной науки понятия «subsistence system» (система обеспечения средствами существования) (Ямсков, 2017, с. 42).

Заслуживают особого внимания исследования Р.М. Сатаева. Автор разрабатывает структуру системы жизнеобеспечения, в которую включает природный блок (освоенная территория, включающая ландшафтные, климатические характеристики и природные ресурсы); материальный блок (хозяйственный коллектив, домашние животные, культивируемые растения); культурный блок (культура жизнеобеспечения - знания, навыки, орудия труда, приспособления) и социальный блок (элементы соционормативной и гуманитарной культуры, в частности ориентированные на достижения психологического комфорта) (Сатаев, 2017, с. 126-134).

Определение структуры и методологии изучения системы жизнеобеспечения продолжается, основным направлением становится сбор данных и изучение систем жизнеобеспечения населения отдельных территорий и археологических культур. Исследование систем жизнеобеспечения древнего населения Верхнего Поволжья ранее не проводилось. По этой причине на основе систематизации всех достижений в описании и изучении систем жизнеобеспечения древних обществ по археологическим данным разработана программа анализа системы жизнеобеспечения, которая включает 59 информативных блоков и 345 признаков; программа была апробирована на материалах археологических памятников Верхнего Поволжья (Беляева, 2019, с. 13-20).

Данная статья посвящена анализу одного из основных информативных блоков системы жизнеобеспечения - системе питания. Для ее описания и изучения выделены следующие группы признаков: первичное производство (собирательство, охота, рыболовство), вторичное производство (земледелие, животноводство, производственная деятельность). На следующем уровне описываются вид каждого из производств, а также орудия, предназначенные для изъятия из природной среды отдельных ресурсов и обработки. На данном уровне фиксируются такие признаки, как остатки растений, остеологические материалы. Именно костные остатки особенно важны для реконструкции системы питания, поскольку являются первичным источником информации об охоте, рыболовстве, разновидностях домашних и промысловых животных, а также некоторых видах производственной деятельности. Однако проблема состоит в том, что лишь небольшая часть костей сохраняется в культурном слое памятника, а также в том, что не всегда в процессе раскопок археологи проводили сбор остеологических материалов, дальнейшее определение и изучение костных остатков.

В настоящем исследовании на основе анализа материалов археологических памятников с каменного до раннего железного века предпринята попытка реконструкции систем жизнеобеспечения населения Верхнего Поволжья и характеристика эволюции системы питания на протяжении нескольких археологических эпох. Была составлена выборка из 32 наиболее информативных 
памятников (рис. 1). В данную выборку включены памятники, на которых обнаружены органические остатки, а также другие признаки, по которым можно реконструировать системы питания.

Незначительное количество отобранных памятников связано с тем, что в части отчетов и публикаций даже при наличии остеологических материалов отсутствуют подробные сведения о них (нет статистики, видового определения и т. д.). При этом, из личного опыта полевой практики, анализ костных остатков даже с одного памятника может значительно расширить наши представления о системе жизнеобеспечения. В ходе археологической разведки 2019 года экспедицией Тверского госуниверситета было обследовано городище Игутьево раннего железного века (Старицкий район Тверской области). В разрушениях культурного слоя и шурфе были собраны и определены все фрагменты костей: КРС (120), лошадь (33), свинья (17), лось (7), МРС (4), человек (1), куница (1), косуля (1), кабан (1) (Лагуткин, 2020, с. 97). Отмечено большое наличие костей лошади на поселении начала I тыс. н. э. и сделано предположение о более широком использовании дьяковским населением лошадей в это время, что уточняет прежние представления о преобладании скотоводства в хозяйстве дьяковской культуры (Лагуткин, 2020, с. 97).

В итоге анализа подобных наиболее информативных памятников с территории Верхнего Поволжья сделаны следующие наблюдения об эволюции системы питания с VIII тыс. до н. э. до І тыс. н. э.

C начала освоения первыми мезолитическими охотниками Верхнего Поволжья регион уже представлял собой уникальную географическую систему. Это выражается во взаимной близости бассейнов крупных рек, плотности озёрных и речных систем; в высоком разнообразии форм рельефа в пределах частей геосистемы. В.M. Воробьев отмечает особо, что «район расположен на отрогах Валдайской возвышенности, хорошо выражен холмисто-грядовой рельеф местности» с многочисленными выходами кремня и глины на поверхность; отсутствуют непреодолимые ландшафтные преграды между частями геосистемы, поскольку территория располагается на Восточно-Европейской равнине в умеренном климате (Воробьев, 1994, с. 3). Все вышеперечисленные факты сформировали особую геосоциальную территорию, кото- рая благодаря речной и природной системе имела возможность как далёких контактов с разными племенами, так и интенсивных местных контактов, что приводило к смешению народов и культур. Но при этом разнообразие форм рельефа приводило к разнородности и обособлению различных племён друг от друга, благодаря чему они не смешивались полностью.

В эпоху мезолита и неолита население Верхнего Поволжья сумело создать достаточно стабильную и сбалансированную систему жизнеобеспечения, не превышающую общего технического развития всего крупного региона лесной полосы в данный период.

Систему питания обеспечивало такой вид первичного производства, как собирательство - остатки плодов ягод и орехов найдены на 4 стоянках (22,2\%), остатки мелких животных (мышь) и моллюсков на 3 (16,6\%). Намного больше обнаружено свидетельств развитого охотничьего хозяйства: кремневые стрелы на 17 памятниках (94,4\%); копья на $7(38,8 \%)$ из дерева и кремня; ножи на 16 $(88,8 \%)$, дротики на $2(11,1 \%)$. Успешное занятие охотой подтверждают находки большого количества остатков костей крупных промысловых животных и крупных хищников (лось, олень, косуля, медведь, волк), значительного количества мелких промысловых животных и пушных зверей (бобр, кабан, барсук, заяц, лисица) - в целом на 90\% памятников (16 из 18); на 4 (22,2\%) стоянках обнаружены кости птиц, которые активно селились по берегам водоёмов. Также зафиксированы следы рыболовства: на 3 (16,6\%) памятниках обнаружены остатки костей рыб или чешуи, на одном памятнике найден острог, на двух - гарпуны и элементы запорной системы (сетка-веши), на трёх - поплавки и грузила.

Следов вторичного производства (земледелия и животноводства) на памятниках мезолита и неолита не обнаружено. Что касается производственной деятельности, то на 4 (22,2\%) стоянках (памятники неолита) найдены фрагменты лепных сосудов для приготовления и хранения пищи. Главным производством являлась обработка камня - найдены камнетёсы на 72,2\% памятников, резцы и лезвия на 88,8\% памятников. (Указаны не только орудия работы по камню, но и результаты деятельности). Достаточно развита была деревообработка: на 6 (33,3\%) памятниках найдены кремневые топоры, на 4 (16,6\%) - тёсла, на 9 (50\%) - свёрла, на 17 (94,4\%) 
- многофункциональные скребки, 22,2\% скобели для сдирания коры с деревьев и их первичного обстругивания.

Поскольку, как показано выше, основой системы питания древнего населения Верхнего Поволжья в эпохи мезолита и неолита были охота, рыболовство и собирательство, она была достаточно легко подвержена воздействию критических природных ситуаций и, как следствие, кризисам в самообеспечении. Населению постоянно приходилось менять места стоянок вследствие миграций охотниче-промысловых животных, для поиска новых месторождений качественного кремня и в случае изменения геоморфологии территории (например, подтопления). Но несмотря на постоянные миграции, сложившиеся в геосистеме Верхнего Поволжья, способы жизнеобеспечения и система питания были комфортной для демографического роста населения в регионе, что подтверждается увеличением количества стоянок к окончанию периода неолита и расширением их культурного разнообразия.

В бронзовом и раннем железном веках стабильность сложившейся на предыдущем этапе системы жизнеобеспечения подтверждается притоком нового населения в регион Верхнего Поволжья (например, представителей фатьяновской и мощинской археологических культур), что вызвало новый этап ее развития. Природно-климатические условия характеризуются некоторым потеплением в среднем на 5 градусов. Начало раннего железного века соответствует сравнительно сухому и теплому суббореальному климату. Средняя температура самого холодного месяца ниже $+5^{\circ} \mathrm{C}$, самого тёплого - выше $+20^{\circ} \mathrm{C}$, что также положительно повлияло на развитие таких видов вторичного производства, как земледелие и скотоводство.

Важно отметить, что все новые виды деятельности привели не просто к поддержанию системы жизнеобеспечения на прежнем уровне, а сделали ее более совершенной. Поселения и жилища бронзового и раннего железного века становятся большими по площади и размерам по сравнению с периодом мезолита и неолита, в связи с чем можно сделать вывод о количественном росте населения. Средняя площадь памятников в неолите равна 218,5 кв. м, средняя площадь жилища 15,1 кв. м. Эти же показатели в период бронзового и раннего железного века соответственно 4277 кв. м и 28,2 кв. м.
Охота продолжает играть значительную роль в системе питания. На $6(33,3 \%)$ памятниках найдены остатки крупных и мелких охотничье-промысловых животных, крупных и мелких хищников (лось, медведь, волк, бобр и т. д.). На 9 (50\%) обнаружены остатки стрел (на $1(5,5 \%)$ - костяные, на $1(5,5 \%)$ - железные, на 7 (38,8\%) - кремневые), на 4 (16,6\%) памятниках - дротики (на $2(11,1 \%)$ из кремня, на $1(5,5 \%)$ из железа); на $2(11,1 \%)$ - копья кремневые и железные; на $11(61,1 \%)$ памятников - ножи и острые пластины из кремня и железа. На 7 (38,8\%) памятниках археологически подтверждено совмещение охоты и занятий рыболовством - найдены остроги и гарпуны, рыболовные крючки и глиняные грузила.

На трех памятниках обнаружены свидетельства занятия земледелием (серпы и зернотёрки). На 9 (50\%) памятниках обнаружены кости свиньи, крупного и мелкого рогатого скота, птицы. На 4 (16,6\%) поселениях найдены кости лошади или элементы упряжи, на одном из которых фигурка в виде коня с седлом. Свидетельством обработки кости являются костяные изделия на $5(27,7 \%)$ памятниках: остроги, наконечники стрел, гребень, заготовка из обработанного ребра животного. Наиболее массовым видом производственной деятельности является изготовление керамики (94\% памятников).

Таким образом, несмотря на развитие земледелия и скотоводства, охота продолжает быть одним из важных элементов системы питания населения Верхнего Поволжья в эпоху бронзы и железа. При количественном распространении орудий охоты происходит их качественное совершенствование, кроме того, анализ остеологического материала позволяет выделить мясное и пушное направления охоты. Рыболовство и собирательство сохраняются как обязательные первичные производства.

Одной из особенностей территории Верхнего Поволжья является размещение поселений разных периодов эпохи первобытности часто на одних и тех же местах концентрации основных ресурсов, необходимых для выживания и ведения хозяйственной деятельности. Леса снабжали население необходимым материалом для строительства и были местами для охоты и собирательства, давали возможность заготавливать в необходимых количествах дрова и древесный уголь для металлургического производства и обжига керамики. 
Водные ресурсы способствовали занятию рыболовством, обеспечивали питьевой водой. Расположение поселений вблизи мест разлива рек также играло важную роль в системе хозяйства: одни получали таким образом необходимые площади для посева зерновых культур, другие - удобные пастбища. Система питания на протяжении тысячелетий первобытной истории представлена всеми видами занятий, которые так или иначе связаны с добычей, приготовлением и сохранением пищи. Население археологических культур эпох мезолита, неолита, бронзы и раннего железного века Верхнего Поволжья, адаптируясь к условиям природной среды, создали успешную систему жизнеобеспечения для развития и роста населения. В процессе выживания они использовали все доступные сырьевые ресурсы: глина, дерево, кость, камень, металлы, вода, рыба, животный мир.
Опыт применения программы описания системы жизнеобеспечения и исследования системы питания населения Верхнего Поволжья показал, что данная программа охватывает большинство возможных элементов, фиксируемых археологами, и применима для других территорий. Открытая база данных позволяет добавлять новую информацию о вновь изученных археологических объектах, что позволит расширить и выводы исследования в дальнейшем. Однако главной проблемой остается недостаточное внимание археологов к сбору и определению остеологического материала памятников, из-за чего усложняется сбор сведений о системе питания в эпоху первобытности. Также сложность изучения систем жизнеобеспечения в целом заключается в плохой сохранности органических материалов до момента полевого исследования, недостаточной разработанности методов объективной оценки имеющихся материалов.

\section{ИСТОЧНИКИ И ЛИТЕРАТУРА}

Арутюнов С.А., Маркарян Э.С., Мкртумян Ю.И. Проблемы исследования культуры жизнеобеспечения этноса // СЭ. 1983. №2. С. 22-31.

Беляева В.С. Объекты археологического наследия как источники по изучению системы жизнеобеспечения древнего населения Тверского края // Культурное наследие русской провинции: материалы Межрегиональной научной конференции, (Тверь - Старица, 9 ноября 2018). Вып. 2. / Отв. ред. С.С. Кутасов. Тверь: ТвГУ, 2019. С. 13-20.

Воробьёв В.М. Великий водораздел Восточной Европы: географо-археологический аспект // Тверской археологический сборник. Вып.1. / Отв. ред. И.Н. Черных. Тверь: Триада, 1994. С 1-6.

Козлов В.И. Жизнеобеспечение этноса: содержание понятия и его экологические аспекты // Этническая экология: теория и практика / Отв. ред. В.И. Козлов. М.: Наука, 1991. С. 14-43.

Крупник И.И. Арктическая этноэкология: модели традиционного природопользования морских охотников и оленеводов Северное Евразии. М.: Наука, 1989. 272 с.

Культура жизнеобеспечения и этнос. / Под ред. Маркаряна Э.С., Арутюнова С.А. Ереван: АН Армянской ССР, 1983. 320 с.

Лагуткин А.В. Отчет об археологических разведках в бассейне р. Волги в пределах Калининского и Старицкого районов / Архив ИА РАН. 2020.

Сатаев Р.М. Общие принципы устройства и функционирования систем жизнеобеспечения традиционных обществ // Вестник археологии, антропологии и этнографии. 2017. № 4. С. 126-134.

Фаган Б., ДеКорс К. Археология. В начале. / пер. с англ. Н.Ю. Струкова М.: Техносфера, 2007. 592 с.

Ямсков А.Н. Системы жизнеобеспечения и хозяйственно-культурные типы // Этнос и среда обитания. Сборник статей по этноэкологии / Отв. ред. Н.А. Дубова. Вып. 5. М.: Старый сад, 2017. С. 36-47.

\section{Информация об авторе:}

Беляева Виктория Сергеевна, Тверской государственный университет (г. Тверь, Россия); belyaewa. vicka2014@yandex.ru

\section{REFERENCES}

Artyunov, S. A., Markaryan, E. S., Mkrtumyan, Yu. I. 1983. In Sovetskaia etnografiia (Soviet Ethnography) (2), 42-62 (in Russian).

Belyaeva, V. S. 2019 In Kutasov, S. S. (ed.). Kul'turnoe nasledie russkoy provintsii Materialy mezhregional'noi nauchnoi konferentsii (Tver, Staritsa, 9 noiabria 2019 goda) (Cultural Heritage of the 
Russian Province: Proceedings of the Interregional Scientific Conference (Tver - Staritsa, November 9, 2018).). Tver : Tver State University, 13-20 (in Russian).

Vorob'ev, V. M. 1994. In Chernykh, I. N. (ed.). Tverskoi arkheologicheskii sbornik (Tver Archaeological Collection of Articles) 1. Tver: "Triada", 1-6 (in Russian).

Kozlov, V. I. 1991. In Kozlov, V. I. (ed.). Etnicheskaia ekologiia: teoriia i praktica (Ethnic Ecology: Theory and Practice). Moscow: "Nauka" Publ., 14-43 (in Russian).

Krupnik, I. I. 1989. Arkticheskaia etnoekologiia: modeli traditsionnogo prirodopol'zovaniia morskih ohotnikov i olenevodov Severnoy Evrazii (Arctic Ethnoecology: Models of Traditional Natural Management of Marine Hunters and Reindeer Herders of Northern Eurasia). Moscow: "Nauka" Publ. (in Russian).

Lagutkin, A. V. 2020. Otchet ob arheologicheskikh razvedkakh v bassejne r. Volgi v predelakh Kalininskogo $i$ Starickogo rajonov (Report on Archaeological Exploration in the Volga River Basin within the Kalininsky and Staritsky Districts). Archive of the Institute of Archaeology of the Russian Academy of Sciences (in Russian).

Kul'tura zhizneobespecheniia i etnos (Sustenance Culture and Ethnos) 1983. In Markaryan, E. S., Artyunov, S. A. (eds.). Yerevan: Academy of Sciences of the Armenian SSR (in Russian).

Sataev, R. M. 2017. In Vestnik arkheologii, antropologii i etnografii (Bulletin of Archaeology, Anthropology and Ethnography) (4), 126-134 (in Russian).

Fagan, B., DeCorse, C. 2007. Arkheologiia. V nachale (In the Beginning an Introduction to Archaeology). Moscow: "Tekhnosfera" Publ. (in Russian).

Yamskov, A. N. 2017. In Dubova, N. A. (ed.). Etnos i sreda obitaniia. (Ethnos and Habitat) 4. Moscow: "Staryi sad" Publ., 36-47 (in Russian).

\section{About the Author:}

Belyayeva Victoria S. Tver State University. Zhelyabov Str., 33 Tver, 170100, Russian Federation; belyaewa.vicka2014@yandex.ru 


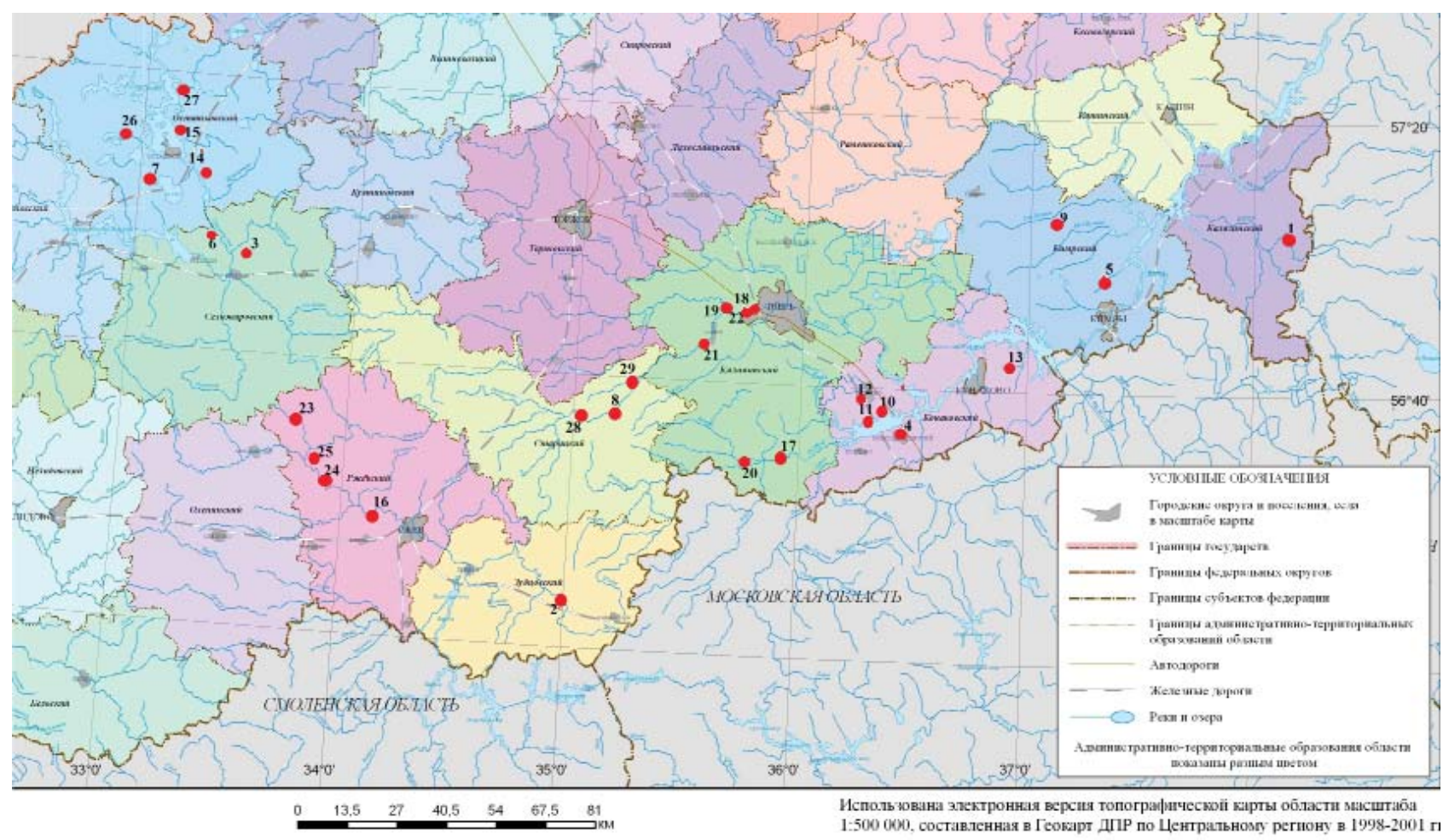

Рис. 1. Карта археологических памятников эпохи первобытности на территории Верхнего Поволжья:

1- Авсерьгово 2 (мезолит); 2 - Троицкое 3 (мезолит); 3 - Озеренки 4 (мезолит); 4 - Озеренки 5 (мезолит); 5 - Прислон 1 (мезолит); 6 - Подол 3 (мезолит); 7 - Нилова Пустынь (мезолит); 8 - Бутово 1 (мезолит); 9 - Тихоново (мезолит); 10 - Озерки 14 (мезолит); 11 - Озерки 16 (мезолит); 12 - Озерки 17 (мезолит); 13 - Озерки 5 (мезолит); 14 - Залесье 1 (неолит); 15 - Залесье 2 (неолит); 16 - Усть-тудовка (неолит); 17 - Новинки 1 (бронзовый век); 18 - Дуденево (бронзовый- ранний железный век); 19 - Избрижье (бронзовый век- ранний железный век); 20 - Непеино (бронзовый- ранний железный век); 21 - Беседы 1 (ранний железный век); 22 - Отмичи (ранний железный век); 23 - Суходол 2 (ранний железный век); 24 - Рогово 2 (ранний железный век); 25 - Осечен (ранний железный век); 26 - Никола Рожок (ранний железный век); 27 - Пески 1 (ранний железный век); 28 - Пентурово (ранний железный век); 29 - Игутьево (ранний железный век).

Fig. 1. Map of archaeological sites of the Primeval period in the territory of the Upper Volga region: 1 - Avsergovo 2 (Mesolithic); 2 - Troitskoe 3 (Mesolithic); 3 - Ozerenki 4 (Mesolithic); 4 - Ozerenki 5 (Mesolithic); 5 - Prislon 1 (Mesolithic); 6 - Podol 3 (Mesolithic); 7 - Nilova Pustyn (Mesolithic); 8 - Butovo 1 (Mesolithic); 9 - Tikhonovo (Mesolithic); 10 - Ozerki 14 (Mesolithic); 11 - Ozerki 16 (Mesolithic); 12 - Ozerki 17 (Mesolithic); 13 - Ozerki 5 (Mesolithic); 14 - Zalesye 1 (Neolithic); 15 - Zalesye 2 (Neolithic); 16 - Ust-Tudovka (Neolithic); 17 - Novinki 1 (Bronze Age); 18 - Dudenevo (Bronze - Early Iron Ages); 19 - Izbryzhie (Bronze - Early Iron Ages); 20 - Nepeino (Bronze - Early

Iron Ages); 21 - Besedy 1 (Early Iron Age); 22 - Otmichi (Early Iron Age); 23 - Sukhodol 2 (Early Iron Age); 24 - Rogovo 2 (Early Iron Age); 25 - Osechen (Early Iron Age); 26 - Nikola Rozhok (Early Iron Age); 27 - Peski 1 (Early Iron Age); 28 - Penturovo (Early Iron Age); 29 - Igutyevo (Early Iron Age). 